\title{
$\Delta G\left(\mathrm{CH}_{2}\right)$ in PEG-Salt and Ucon-Salt Aqueous Two-Phase Systems
}

\author{
Sara C. Silvério, ${ }^{\dagger, *}$ Pedro P. Madeira, ${ }^{\dagger, *}$ Oscar Rodríguez, ${ }^{\dagger}$ José A. Teixeira, ${ }^{\ddagger}$ and Eugénia A. Macedo*, ${ }^{* \dagger}$ \\ Laboratory of Separation and Reaction Engineering, Department of Chemical Engineering, Faculdade de Engenharia da \\ Universidade do Porto, Rua Dr. Roberto Frias, s/n 4200-465 Porto, Portugal, and IBB-Institute for Biotechnology and \\ Bioengineering, Centre for Biological Engineering, Universidade do Minho, Campus de Gualtar 4710-057, Braga, Portugal
}

\begin{abstract}
Three new phase diagrams for polymer-salt aqueous two-phase systems (ATPS) at $23{ }^{\circ} \mathrm{C}$ are presented. Then, partition coefficients for a series of five dinitrophenylated amino acids were obtained experimentally in five polymer-salt ATPS. The ATPS were obtained combining a polymer, polyethylene glycol (PEG) or Ucon (a random copolymer of $50 \%$ ethylene oxide and $50 \%$ propylene oxide), and a $\mathrm{salt}\left(\mathrm{Na}_{2} \mathrm{SO}_{4}\right.$, $\left(\mathrm{NH}_{4}\right)_{2} \mathrm{SO}_{4}$, or $\left.\mathrm{Li}_{2} \mathrm{SO}_{4}\right)$. The series of amino acids allowed the calculation of the free energy of transfer of a methylene group, which is used as a measure of the relative hydrophobicity of the equilibrium phases. Ucon-rich phases proved to have a higher affinity for methylene groups than PEG which suggests a more efficient biphasic separation system with lower cross-contamination.
\end{abstract}

\section{Introduction}

Aqueous two-phase systems (ATPS) are biphasic systems that appear when two aqueous solutions of certain polymers, or polymers and salts, are mixed above some critical conditions (temperature and composition). ${ }^{1-3}$ ATPS have been used as extractive systems in biotechnological applications to recover target biomolecules, as they bring together the easiness of an extraction process (a well-known separation unit of chemical engineering, robust, easy to scale up, which can be directly applied to fermentation broths) and the suitability of an aqueous solution for biomolecules (which are so sensitive to their medium). Nevertheless, this use at an industrial level is not extensive. The lack of a fundamental, predictive tool to understand the partitioning of solutes in ATPS is among the reasons for its underuse. Thus, the successful application of partitioning in ATPS can benefit from understanding the mechanisms of solute distribution in these systems and their properties at a molecular level.

Among the properties of the systems, the free energy of transfer of a methylene group between the coexisting phases, $\Delta G\left(\mathrm{CH}_{2}\right)$, has been shown ${ }^{3-5}$ to be useful for the characterization of ATPS of different polymer and salt compositions. In this work, the partition coefficients of a series of dinitrophenylated amino acids in five different polymer-salt ATPS are presented. The free energies of transfer of a methylene group between the equilibrium phases were calculated for each system from the partition coefficients. This free energy of transfer is a measure of the relative hydrophobicity of the phases, which is an important factor governing protein partition.

\section{Experimental Section}

Materials. Polyethylene glycol, PEG (average molecular weight 8000), was obtained from Sigma. Ucon 50-HB-5100, Ucon, a random copolymer (average molecular weight $M_{\mathrm{r}}=$ 3900 ) of $50 \%$ ethylene oxide and $50 \%$ propylene oxide, was

* Corresponding author. Phone: +351 22508 1653. Fax: +351 22508

1674. E-mail: eamacedo@fe.up.pt.

Faculdade de Engenharia da Universidade do Porto.

$\div$ Universidade do Minho. obtained from Union Carbide (NY, USA). Sodium sulfate, $\mathrm{Na}_{2} \mathrm{SO}_{4}$, and ammonium sulfate, $\left(\mathrm{NH}_{4}\right)_{2} \mathrm{SO}_{4}$, were supplied by Merck (anhydrous GR for analysis, > $99.0 \%$, and Suprapur, $>99.9999 \%$, respectively). Lithium sulfate, $\mathrm{Li}_{2} \mathrm{SO}_{4}$, was supplied by Fluka (purum p.a., > 98.0 \%). All dinitrophenylated (DNP) amino acids were obtained from Sigma: $N$-(2,4-dinitrophenyl)-glycine, $N$-(2,4-dinitrophenyl)-L-alanine, $N$-(2,4-dinitrophenyl)-DL- $n$-valine, $N$-(2,4-dinitrophenyl)-DL- $n$-leucine, $N$-(2,4dinitrophenyl)-DL- $\alpha$-amino- $n$-caprylic acid. All products were used as received without further purification. Stock solutions of each chemical were prepared (ca. $50 \mathrm{wt} \%$ for polymers, 17 wt $\%$ for $\left(\mathrm{NH}_{4}\right)_{2} \mathrm{SO}_{4}$ and $\mathrm{Na}_{2} \mathrm{SO}_{4}, 20 \mathrm{wt} \%$ for $\mathrm{Li}_{2} \mathrm{SO}_{4}, 0.2 \mathrm{wt}$ $\%$ for DNP amino acids), and all concentrations were obtained gravimetrically after liofilization (ScanVac, model CoolSafe 554) of the stock solutions. Distilled water was used for all diluting purposes. All weighing was carried out on an Adam Equipment balance model AAA250L, precise to within $\pm 0.2 \mathrm{mg}$.

Aqueous Two-Phase Systems. Phase diagrams for PEG$\mathrm{Li}_{2} \mathrm{SO}_{4}, \mathrm{Ucon}-\mathrm{Li}_{2} \mathrm{SO}_{4}$, and Ucon- $\mathrm{Na}_{2} \mathrm{SO}_{4}$ ATPS were obtained experimentally as described by Willauer and co-workers. ${ }^{5}$ First, the binodal curve was determined using the cloud-point method. ${ }^{6}$ Known masses of polymer and salt stock solutions were added to an assay tube to obtain a heterogeneous system. The tube was shaken and placed in a thermostatic bath (Techne Tempette TE-8D) at $(23 \pm 0.2)^{\circ} \mathrm{C}$. Known amounts of water were added to the tube until a homogeneous system was obtained (the tubes were shaken and then placed back into the bath before inspection between each water addition). The binodal curve was determined for each system using different initial masses of polymer and salt stock solutions. Then, the volumes and densities of the equilibrium phases for three tie-lines were obtained experimentally. Known amounts of polymer and salt stock solutions were added to a decanting ampule to obtain a heterogeneous system, and it was vigorously shaken and then allowed to separate for at least $24 \mathrm{~h}$. The volume of each phase was marked in the ampule, and samples of both phases were withdrawn. The volume of each phase was obtained from the mass of water which occupied the same volume as the corresponding phase, and the densities were measured using pycnometers. Then, the ends of the tie-lines were calculated using material balances, 
the phases' mass ratio, and the binodal curve. The experimental binodal curve was adjusted to the empirical equation suggested by Merchuk and co-workers ${ }^{7}$

$$
y=a \cdot \exp \left(b \cdot x^{0.5}-c \cdot x^{3}\right)
$$

where $y$ and $x$ are the polymer and salt compositions in mass fraction, respectively, and $a, b$, and $c$ are adjustable parameters. The mass balance applied to a tie-line gives the relationship

$$
M_{\mathrm{F}}=M_{\mathrm{T}}+M_{\mathrm{B}}
$$

where $M$ stands for mass and subscripts F, T, and B indicate feed, top, and bottom phases. Defining the top phase mass fraction $R$

$$
R=\frac{M_{\mathrm{T}}}{M_{\mathrm{B}}+M_{\mathrm{T}}}
$$

then the material balance allows calculation of the composition of a component (polymer or salt) in the top phase from its feed and bottom compositions

$$
\begin{aligned}
& x_{\mathrm{T}}=\frac{x_{\mathrm{F}}}{R}-\frac{1-R}{R} x_{\mathrm{B}} \\
& y_{\mathrm{T}}=\frac{y_{\mathrm{F}}}{R}-\frac{1-R}{R} y_{\mathrm{B}}
\end{aligned}
$$

The ends of the tie-lines were then calculated from eqs 1,4 , and 5 .

Partition Coefficients. The partition coefficients of five dinitrophenylated amino acids were measured experimentally from the tie-lines previously obtained. Six replicates of the feed composition of a given tie-line were prepared in eppendorf tubes containing (0 to 100) $\mathrm{mg}$ of a given DNP amino acid stock solution to assess aggregation effects. The tubes were thoroughly mixed on a vortex mixer for $2 \mathrm{~min}$, and then the phases were resolved using centrifugation $\left(10^{4} \mathrm{rpm}\right.$ for $\left.15 \mathrm{~min}\right)$. Samples of each phase were withdrawn and conveniently diluted, and the absorbances at $362 \mathrm{~nm}$ were measured on a UV-vis spectrometer (Thermo Electron Corp., model UV1). All absorbances were below 0.8 . The partition coefficient was calculated as the slope of the straight line obtained when comparing the concentration $\left(\mathrm{mg} \cdot \mathrm{mL}^{-1}\right)$ in the top phase against that in the bottom phase, corrected with the corresponding dilution factor, $\mathrm{DF}_{\text {phase }}$ (the final volume divided by the initial volume), thus

$$
K=\frac{\operatorname{Abs}(\text { top }) \cdot \mathrm{DF}_{\text {top }}}{\operatorname{Abs}(\text { bottom }) \cdot \mathrm{DF}_{\text {bottom }}}
$$

The top phase was the polymer-rich phase, and the bottom phase the salt-rich phase, in all ATPS except for Ucon- $\left(\mathrm{NH}_{4}\right)_{2} \mathrm{SO}_{4}$. This system showed phase inversion, and for convenience, the partition coefficient in this system is defined as the ratio between the solute compositions in the polymer-rich and the salt-rich phases (so it can be compared with all the other partition coefficients).

\section{Results and Discussion}

Phase Diagrams. The ends of the tie-lines for PEG- $\mathrm{Li}_{2} \mathrm{SO}_{4}$, Ucon- $\mathrm{Li}_{2} \mathrm{SO}_{4}$, and Ucon- $\mathrm{Na}_{2} \mathrm{SO}_{4}$ ATPS calculated from eqs 1,4 , and 5 are given in Table 1 . The tie-line lengths (TLL) and slopes of the tie-lines (STL) shown in Table 1 were calculated according to

$$
\begin{gathered}
\mathrm{STL}=\frac{\Delta P}{\Delta S} \\
\mathrm{TLL}=\left(\Delta P^{2}+\Delta S^{2}\right)^{1 / 2}
\end{gathered}
$$

where $\Delta P$ and $\Delta S$ are the differences in polymer and salt composition, respectively, between the equilibrium phases.

Phase diagrams of PEG- $\left(\mathrm{NH}_{4}\right)_{2} \mathrm{SO}_{4}, \mathrm{PEG}-\mathrm{Na}_{2} \mathrm{SO}_{4}$, and Ucon- $\left(\mathrm{NH}_{4}\right)_{2} \mathrm{SO}_{4}$ ATPS were taken from the literature. ${ }^{3,8,9}$ The phase diagrams for the ATPS studied in this work are compared in Figure 1. Inspection of this figure shows that the heterogeneous region using Ucon as the phase-forming polymer is larger than using PEG, for the three different salts. Also, it is larger for systems using $\mathrm{Na}_{2} \mathrm{SO}_{4}$. The effect of $\mathrm{Li}_{2} \mathrm{SO}_{4}$ and $\left(\mathrm{NH}_{4}\right)_{2} \mathrm{SO}_{4}$ in the ATPS is very similar in the presence of PEG according to previously reported results, ${ }^{10}$ but with $\mathrm{Ucon}-\mathrm{Li}_{2} \mathrm{SO}_{4}$ gives a larger heterogeneous region.

Partition Coefficients. The partitioning experiments were performed in five different ATPS and compared to previous results from PEG- $\mathrm{Na}_{2} \mathrm{SO}_{4}$ ATPS. ${ }^{8}$ Feed compositions of the tie-lines used are indicated in Table 2. The experimental partition coefficients of DNP amino acids and their errors are given in Tables 3 and 4 for the systems containing PEG and Ucon, respectively. Figure 2 presents the logarithms of partition coefficients as a function of the number of equivalent methylene groups in the aliphatic side chain of homologous DNP amino acids. It can be seen from Figure 2 that the logarithms of partition coefficients are linearly related to the number of methylene units

$$
\ln K=C+E \cdot n\left(\mathrm{CH}_{2}\right)
$$

where $n\left(\mathrm{CH}_{2}\right)$ is the average equivalent number of methylene $\left(\mathrm{CH}_{2}\right)$ groups in the amino acid aliphatic side-chain and $C$ and $E$ are constants. The physical meaning of both parameters $C$ and $E$ has been discussed previously. ${ }^{3}$ Parameter $E$ is related to the free energy of transfer of a methylene group between the phases, $\Delta G\left(\mathrm{CH}_{2}\right)$, as

$$
\Delta G\left(\mathrm{CH}_{2}\right)=-R \cdot T \cdot E
$$

with $R$ being the universal gas constant and $T$ the absolute temperature. The parameter $E$ is a measurement of the difference

\begin{tabular}{|c|c|c|c|c|c|c|c|}
\hline \multicolumn{2}{|c|}{ feed } & \multicolumn{2}{|c|}{ top phase } & \multicolumn{2}{|c|}{ bottom phase } & \multirow[b]{2}{*}{ TLL } & \multirow[b]{2}{*}{ STL } \\
\hline salt & polymer & salt & polymer & salt & polymer & & \\
\hline \multicolumn{8}{|c|}{$\mathrm{PEG}-\mathrm{Li}_{2} \mathrm{SO}_{4}$ ATPS } \\
\hline 0.0950 & 0.1300 & 0.0591 & 0.2296 & 0.1381 & 0.0102 & 0.233 & -2.78 \\
\hline $0.1000^{a}$ & 0.1400 & 0.0514 & 0.2628 & 0.1541 & 0.0031 & 0.279 & -2.53 \\
\hline 0.1050 & 0.1500 & 0.0450 & 0.2907 & 0.1686 & 0.0008 & 0.315 & -2.35 \\
\hline \multicolumn{8}{|c|}{$\mathrm{Ucon}-\mathrm{Li}_{2} \mathrm{SO}_{4}$ ATPS } \\
\hline $0.0570^{a}$ & 0.1200 & 0.0276 & 0.2721 & 0.0791 & 0.0058 & 0.271 & -5.17 \\
\hline 0.0550 & 0.1100 & 0.0307 & 0.2427 & 0.0727 & 0.0129 & 0.234 & -5.48 \\
\hline 0.0600 & 0.1300 & 0.0258 & 0.2894 & 0.0875 & 0.0017 & 0.294 & -4.66 \\
\hline \multicolumn{8}{|c|}{ Ucon $-\mathrm{Na}_{2} \mathrm{SO}_{4}$ ATPS } \\
\hline $0.0413^{a}$ & 0.1676 & 0.0162 & 0.2970 & 0.0733 & 0.0021 & 0.300 & -5.16 \\
\hline 0.0540 & 0.1751 & 0.0105 & 0.3712 & 0.0928 & 0.0001 & 0.380 & -4.51 \\
\hline 0.0500 & 0.1700 & 0.0136 & 0.3285 & 0.0891 & 0.0001 & 0.337 & -4.35 \\
\hline
\end{tabular}
between the affinities of the two phases for a $\mathrm{CH}_{2}$ group; i.e., it is a measurement of the relative hydrophobicity of the phases. Parameter $C$ gives the contribution of the rest of the solute molecule (the nonalkyl part) to the logarithm of the partition coefficient. $^{3}$ These two parameters were obtained by linear regression and are presented in Table 5, together with the

Table 1. Compositions of Feed, Top, and Bottom Phases of the Tie-Lines Determined in Mass Fraction and Tie-Line Length and Slope Calculated with Equations 7 and 8

\footnotetext{
${ }^{a}$ Tie-lines used for partitioning experiments.
} 

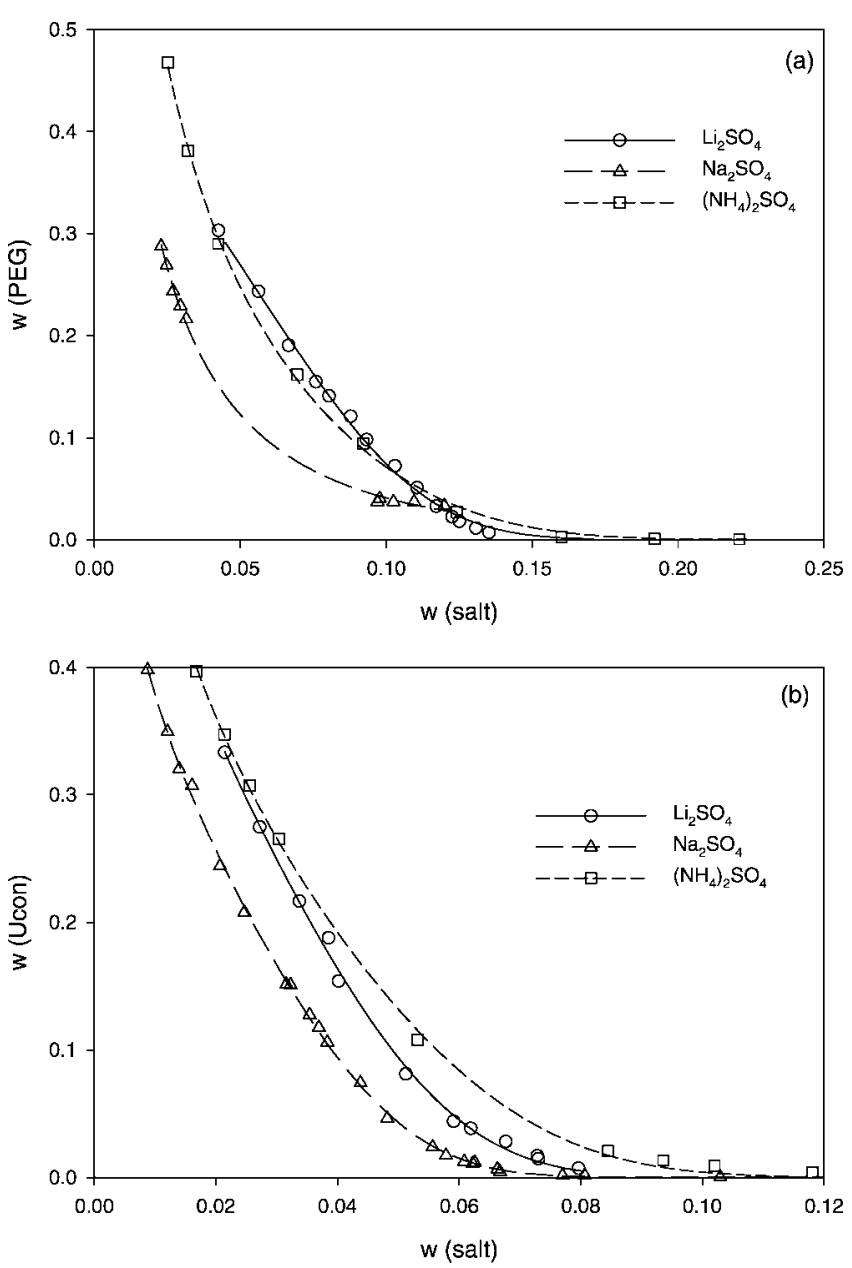

Figure 1. Binodal curves of (a) PEG-salt and (b) Ucon-salt ATPS at 23 ${ }^{\circ} \mathrm{C}$.

Table 2. Tie-Line Feed Compositions for Partitioning Experiments, In Mass Fraction

\begin{tabular}{lccl}
\hline \multicolumn{1}{c}{ system } & salt & polymer & \multicolumn{1}{c}{ ref } \\
\hline $\mathrm{PEG}-\mathrm{Na}_{2} \mathrm{SO}_{4}$ & 0.0727 & 0.1186 & 8 \\
$\mathrm{PEG}-\mathrm{Li}_{2} \mathrm{SO}_{4}$ & 0.1000 & 0.1400 & this work \\
$\mathrm{PEG}-\left(\mathrm{NH}_{4}\right)_{2} \mathrm{SO}_{4}$ & 0.1100 & 0.1250 & 3 \\
$\mathrm{Ucon}-\mathrm{Na}_{2} \mathrm{SO}_{4}$ & 0.0413 & 0.1676 & this work \\
Ucon- $\mathrm{Li}_{2} \mathrm{SO}_{4}$ & 0.0570 & 0.1200 & this work \\
Ucon- $\left(\mathrm{NH}_{4}\right)_{2} \mathrm{SO}_{4}$ & 0.0650 & 0.1260 & 9
\end{tabular}

Table 3. Partition Coefficients, $K_{i}$, for DNP Amino Acids in PEG-Salt ATPS at $23^{\circ} \mathrm{C}$

\begin{tabular}{lccc}
\hline DNP AA & PEG- $\mathrm{Na}_{2} \mathrm{SO}_{4}{ }^{a, b}$ & ${\mathrm{PEG}-\mathrm{Li}_{2} \mathrm{SO}_{4}{ }^{a}}$ & $\mathrm{PEG}-\left(\mathrm{NH}_{4}\right)_{2} \mathrm{SO}_{4}{ }^{a}$ \\
\hline DNP Gly & $4.84 \pm 0.08$ & $12.51 \pm 0.25$ & $7.79 \pm 0.21$ \\
DNP Ala & $5.27 \pm 0.08$ & $15.61 \pm 0.31$ & $10.27 \pm 0.31$ \\
DNP Val & $7.89 \pm 0.17$ & $22.76 \pm 0.44$ & $15.34 \pm 0.38$ \\
DNP Leu & $10.45 \pm 0.20$ & $30.57 \pm 0.77$ & $22.03 \pm 0.50$ \\
DNP AOc & $20.06 \pm 0.49$ & $62.08 \pm 2.23$ & $51.88 \pm 0.83$
\end{tabular}

${ }^{a}$ For system compositions, see Table 2. ${ }^{b}$ From ref 8.

coefficient of determination, $r^{2}$, and the free energy of transfer of a methylene group, $\Delta G\left(\mathrm{CH}_{2}\right)$, calculated with eq 10 .

The values of $\Delta G\left(\mathrm{CH}_{2}\right)$ for systems containing PEG are smaller (less negative) than the corresponding values for Ucon-ATPS. Such trends indicate that PEG-rich phases are less hydrophobic than Ucon-rich phases, which could be expected from the polymer structure: both polymers are polyethers, PEG is an ethylene oxide homopolymer, and Ucon is a random copolymer of ethylene oxide and propylene oxide. The larger alkyl chain of the propylene oxide units stands for a higher
Table 4. Partition Coefficients, $K_{i}$, for DNP Amino Acids in Ucon-Salt ATPS at $23{ }^{\circ} \mathrm{C}$

\begin{tabular}{lccc}
\hline DNP AA & Ucon- $\mathrm{Na}_{2} \mathrm{SO}_{4}{ }^{a}$ & $\mathrm{Ucon}-\mathrm{Li}_{2} \mathrm{SO}_{4}{ }^{a}$ & $\mathrm{Ucon}-\left(\mathrm{NH}_{4}\right)_{2} \mathrm{SO}_{4}{ }^{a}$ \\
\hline DNP Gly & $8.27 \pm 0.11$ & $7.25 \pm 0.13$ & $12.43 \pm 0.17$ \\
DNP Ala & $9.95 \pm 0.20$ & $7.68 \pm 0.21$ & $16.12 \pm 0.22$ \\
DNP Val & $15.73 \pm 0.25$ & $10.56 \pm 0.20$ & $29.27 \pm 0.39$ \\
DNP Leu & $20.78 \pm 0.31$ & $14.71 \pm 1.0$ & $39.40 \pm 0.51$ \\
DNP AOc & $63.02 \pm 1.18$ & $34.40 \pm 0.94$ & $127.12 \pm 1.52$
\end{tabular}

${ }^{a}$ For system compositions, see Table 2 .
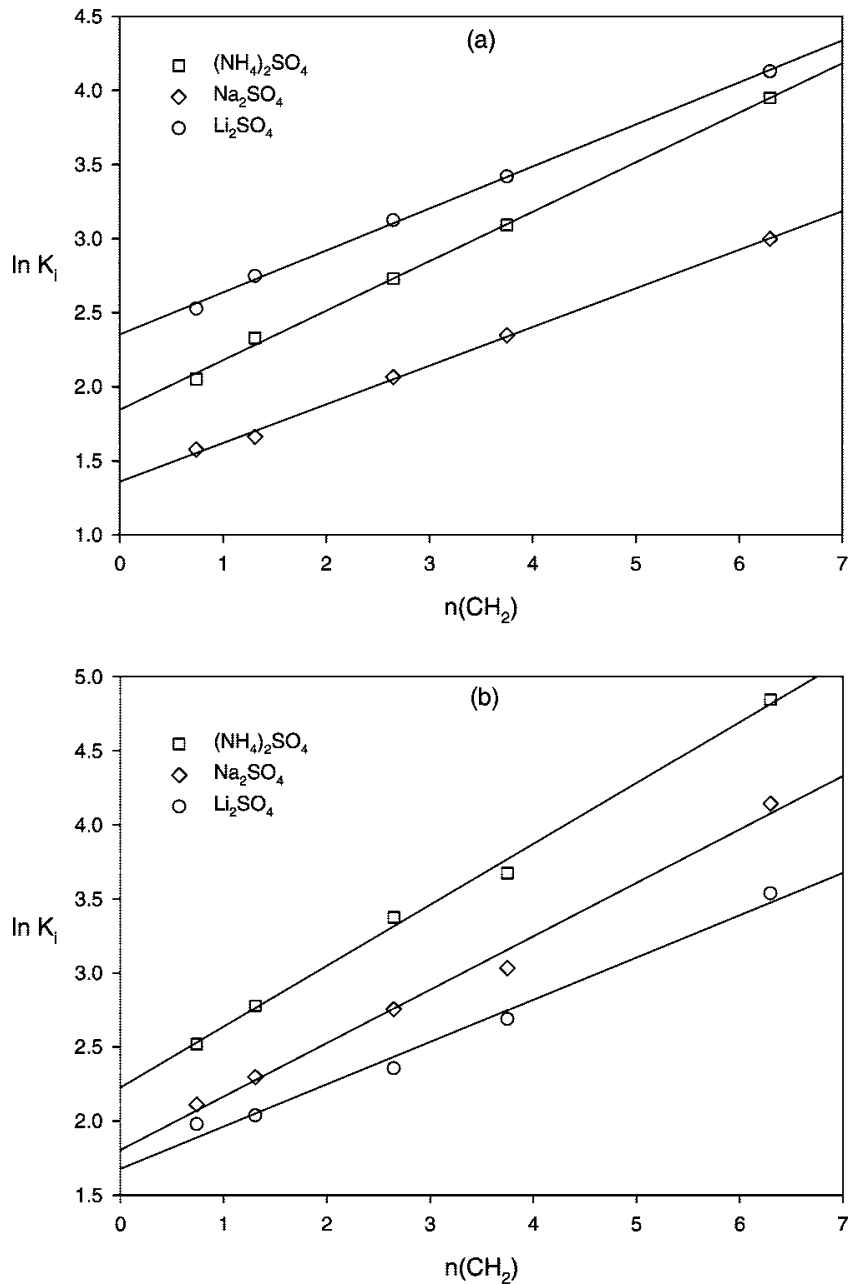

Figure 2. Logarithm of partition coefficients for a series of DNP amino acids in (a) PEG-salt and (b) Ucon-salt ATPS at $23{ }^{\circ} \mathrm{C}$. The lines are linear regressions of the experimental data.

Table 5. Parameters $C$ and $E$ (Equation 9) and $\Delta G\left(\mathrm{CH}_{2}\right)$ (Equation 10) for the Six ATPS at $23{ }^{\circ} \mathrm{C}$

\begin{tabular}{lcccc}
\hline \multicolumn{1}{c}{ system } & & & & $\frac{-\Delta G\left(\mathrm{CH}_{2}\right)}{n}$ \\
\hline PEG- $-\mathrm{Na}_{2} \mathrm{SO}_{4}$ & $1.36 \pm 0.02$ & $0.261 \pm 0.006$ & 0.998 & 0.153 \\
PEG $-\mathrm{Li}_{2} \mathrm{SO}_{4}$ & $2.35 \pm 0.02$ & $0.284 \pm 0.006$ & 0.998 & 0.167 \\
$\mathrm{PEG}-\left(\mathrm{NH}_{4}\right)_{2} \mathrm{SO}_{4}$ & $1.85 \pm 0.03$ & $0.334 \pm 0.008$ & 0.998 & 0.196 \\
$\mathrm{Ucon}-\mathrm{Na}_{2} \mathrm{SO}_{4}$ & $1.80 \pm 0.07$ & $0.361 \pm 0.019$ & 0.992 & 0.212 \\
$\mathrm{Ucon}-\mathrm{Li}_{2} \mathrm{SO}_{4}$ & $1.59 \pm 0.05$ & $0.304 \pm 0.013$ & 0.995 & 0.179 \\
Ucon- $\left(\mathrm{NH}_{4}\right)_{2} \mathrm{SO}_{4}$ & $2.23 \pm 0.05$ & $0.411 \pm 0.015$ & 0.996 & 0.242
\end{tabular}

hydrophobicity of Ucon. This can also be related to Ucon providing a biphasic system with a heterogeneous region larger than that of PEG (Figure 1), as discussed above.

It is important to state that Ucon is a thermoseparating polymer: its aqueous solution splits into two phases above a certain lower critical solution temperature (LCST). ${ }^{9,11}$ This facilitates the recovery of a target solute from the polymer-rich 
phase just using a temperature change. Together with the higher hydrophobicity, it makes Ucon an alternative to PEG as a phaseforming polymer in ATPS.

\section{Conclusions}

Phase diagrams for three polymer-salt ATPS are presented: $\mathrm{PEG}-\mathrm{Li}_{2} \mathrm{SO}_{4}, \mathrm{Ucon}-\mathrm{Li}_{2} \mathrm{SO}_{4}$, and $\mathrm{Ucon}-\mathrm{Na}_{2} \mathrm{SO}_{4}$ at $23{ }^{\circ} \mathrm{C}$.

Partition coefficients for a series of five DNP amino acids were obtained experimentally in five different polymer-salt ATPS, using PEG and Ucon polymers with three sulfate salts: $\mathrm{Li}_{2} \mathrm{SO}_{4}, \mathrm{Na}_{2} \mathrm{SO}_{4}$, and $\left(\mathrm{NH}_{4}\right)_{2} \mathrm{SO}_{4}$. Free energies of transfer for a methylene group were calculated for the five systems from the partition coefficients.

Ucon showed a higher hydrophobicity than PEG, and $\left(\mathrm{NH}_{4}\right)_{2} \mathrm{SO}_{4}$ had the smallest. Because of its higher hydrophobicity, Ucon provides a biphasic system with a heterogeneous region larger than that of PEG (Figure 1). Thus, phase splitting is better and cross-contamination of the phases smaller. Ucon is also a thermoseparating polymer, thus its use instead of PEG may be an interesting alternative.

\section{Literature Cited}

(1) Albertsson, P.Å. Partition of cell particles and macromolecules, 2nd ed.; John Wiley \& Sons Inc.: New York, 1971.

(2) Walter, H.; Brooks, D. E.; Fisher, D., Eds.; Partitioning in Aqueous Two-Phase Systems: Theory, Methods, Use, and Applications to Biotechnology; Academic Press: Orlando, Florida, 1985.

(3) Zaslavsky, B. Y. Aqueous two-phase partitioning; Marcel Dekker Inc.: New York, 1995.

(4) Willauer, H. D.; Huddleston, J. G.; Rogers, R. D. Solvent Properties of Aqueous Biphasic Systems Composed of Polyethylene Glycol and Salt Characterized by the Free Energy of Transfer of a Methylene
Group between the Phases and by a Linear Solvation Energy Relationship. Ind. Eng. Chem. Res. 2002, 41, 2591-2601.

(5) Willauer, H. D.; Huddleston, J. G.; Rogers, R. D. Solute Partitioning in Aqueous Biphasic Systems Composed of Polyethylene Glycol and Salt: The Partitioning of Small Neutral Organic Species. Ind. Eng. Chem. Res. 2002, 41, 1892-1904.

(6) Othmer, D. F.; White, R. E.; Trueger, E. Liquid-Liquid Extraction Data. Ind. Eng. Chem. 1940, 33, 1240-1248.

(7) Merchuk, J. C.; Andrews, B. A.; Asenjo, J. A. Aqueous two-phase systems for protein separation. Studies on phase inversion. J. Chromatogr. B 1998, 711, 285-293.

(8) Rodriguez, O.; Silvério, S. C.; Madeira, P. P.; Teixeira, J. A.; Macedo, E. A. Physicochemical Characterization of the PEG8000- $\mathrm{Na}_{2} \mathrm{SO}_{4}$ Aqueous Two-Phase System. Ind. Eng. Chem. Res. 2007, 46, 81998204.

(9) Pereira, M.; Wu, Y.-T.; Madeira, P.; Venâncio, A.; Macedo, E.; Teixeira, J. A. Liquid-Liquid Equilibrium Phase Diagrams of New Aqueous Two-Phase Systems: Ucon 50-HB5100 + Ammonium Sulfate + Water, Ucon 50-HB5100 + Poly(vinyl alcohol) + Water, Ucon 50-HB5100 + Hydroxypropyl Starch + Water, and Poly(ethylene glycol) $8000+$ Poly(vinyl alcohol) + Water. J. Chem. Eng. Data 2004, 49, 43-47.

(10) Huddleston, J. G.; Willauer, H. D.; Rogers, R. D. Phase Diagram Data for Several PEG + Salt Aqueous Biphasic Systems at $25^{\circ} \mathrm{C}$. J. Chem. Eng. Data 2003, 48, 1230-1236.

(11) Johansson, H.-O.; Persson, J.; Tjerneld, F. Thermoseparating Water/ Polymer System: A Novel One-Polymer Aqueous Two-Phase System for Protein Purification. Biotechnol. Bioeng. 1999, 66, 24-257.

Received for review March 3, 2008. Accepted April 23, 2008. S.C.S. acknowledges the scholarship within the Project POCI/EQU/60720/2004 from Fundação para a Ciência e a Tecnologia (FCT, Portugal). P.P.M. acknowledges the financial support through Grant SFRH/BPD/24271/ 2005 and O.R. through Programme "Ciência 2007", both from FCT. Financial support for this work was in part provided by LSRE financing by FEDER/POCI/2010, for which the authors are thankful.

JE800154Y 